Research Article

\title{
The Synergistic Antiwear Performances of Organic Titanium Compounds Containing Sulfur with Borate Ester Additive
}

\author{
Xin Xu, Jian-Qiang Hu $(\mathbb{D}$, Feng Xie, Li Guo, Jun Ma, and Shi-Zhao Yang $\mathbb{D}$ \\ Department of Aviation Oil and Material, Air Force Logistic College, Xuzhou, China \\ Correspondence should be addressed to Jian-Qiang Hu; hjq555918@sohu.com and Shi-Zhao Yang; ysz20045@126.com
}

Received 25 June 2018; Accepted 27 September 2018; Published 1 November 2018

Academic Editor: Salvatore Magazù

Copyright $\odot 2018$ Xin Xu et al. This is an open access article distributed under the Creative Commons Attribution License, which permits unrestricted use, distribution, and reproduction in any medium, provided the original work is properly cited.

\begin{abstract}
Two oil-soluble organic titanium compounds (OTCs) such as titanium dialkyldithiocarbamate (TiDDC) and sulfurized titanate (TiS) were synthesized and identified by Fourier-transform infrared spectroscopy (FTIR). The antiwear and extreme pressure properties of TiDDC or TiS with borate ester containing nitrogen (BNO) additive in mineral base oils were evaluated by four ball tester. The results show that TiDDC and TiS not only possess good antiwear and load-carrying properties, respectively, but also exhibit good antiwear synergism with BNO additive without impairing extreme pressure performances. Moreover, the synergistic antiwear properties of the said additives are improved significantly under the optimum additives ratios. The topography of wear scar and the composition and chemical states of typical elements on the rubbing surfaces were analyzed by scanning electron microscopy (SEM) with energy dispersive X-ray (EDX) and X-ray photoelectron spectrometer (XPS). The proposed synergistic antiwear mechanism involves an effective interaction between TiDDC or TiS and BNO additive, respectively.
\end{abstract}

\section{Introduction}

In the field of lubrication, zinc dialkyldithiophosphate (ZDDP) has been widely utilized as a multifunctional lubricant additive exhibiting good antiwear and antioxidative properties in engine oils [1-5]. However, the existence of phosphorus in ZDDP would cause the catalyst to be poisoned, thus shortening the useful life of the catalytic converter [6,7]. In addition, the existence of zinc element contributes to the emission of particulates in the exhaust [8]. The demand for reduction of phosphorous content in engine oils has forced the oil suppliers to improve the formulation of lubricant additives $[9,10]$. Moreover, the International Lubricant Standardization and Approval Committee (ILSAC) provided the GF-5 performance standards that place limits of $0.08 \%$ max. on phosphorus in the finished engine oils, so as to improve fuel economy, environmental protection, and emissions system compatibility [11-13]. So, it is desirable to partially or totally replace ZDDP with other lubricant additives without reducing the performances of formulated engine oils.

Organic titanium compounds (PFTCs) as lubricant additives are capable of enhancing antiwear, antioxidation, and fiction reducing performances in the boundary lubrication regime and improving fuel economy in engine oils [14-17].

The required function of lubricants is achieved by appropriate balance of different lubricating additives [18]. Investigations of synergistic effects that can optimize the composition and expand the areas of application of additive packages are of considerable scientific and practical interests [19-21]. In the present study, the synergistic antiwear and load-carrying properties of borate ester containing nitrogen (BNO) with titanium dialkyldithiocarbamate (TiDDC) or sulfurized titanate (TiS), respectively, were investigated, and subsequent exploitation of the results for the development of a synergistic antiwear additives composition were offered.

\section{Experimental}

2.1. Oil Samples and Additives. The organic borate ester additive containing nitrogen (BNO) was purchased from Vanderbilt Company; and titanium dialkyldithiocarbamate (TiDDC) and sulfurized titanate (TiS) were synthesized in the lab. All concentrations of additives used in the 
investigation are expressed in percentages by weight if not stated otherwise. The model additives in different proportions were weighed, mixed, and dissolved in $150 \mathrm{SN}$ mineral base oil with viscosity $5.1 \mathrm{~mm}^{2} / \mathrm{s}$ at $100^{\circ} \mathrm{C}$.

2.2. Characterization of TiDDC and TiS. The structures of TiDDC and TiS were confirmed through Fourier-transform infrared spectroscopy (FTIR) with PerkinElmer Spectrum Two Infrared Instrument. The stretching vibration absorption band of $\mathrm{N}-\mathrm{H}$ at $3400 \mathrm{~cm}^{-1}$ was observed in TiDDC. The bending vibration absorption band of $\mathrm{C}-\mathrm{N}$ at $1513 \mathrm{~cm}^{-1}$ was observed in TiDDC, which confirmed the formation of the secondary amine compound. The asymmetric and symmetric stretching vibration absorption bands of $\mathrm{C}-\mathrm{H}$ were observed at 2965 and $2902 \mathrm{~cm}^{-1}$, respectively, which indicated the existence of methyl in the product. The stretching vibration absorption bands of $\mathrm{C}=\mathrm{S}$ and $\mathrm{C}-\mathrm{S}$ were detected at $1125 \mathrm{~cm}^{-1}$ and $967 \mathrm{~cm}^{-1}$, respectively, and the stretching vibration absorption bands of Ti-S was detected at $521 \mathrm{~cm}^{-1}$, which confirmed main functional groups of TiDDC.

The same C-H bands were observed at 2929 and $2872 \mathrm{~cm}^{-1}$ in TiS, which were the characteristic peak of methene. The stretching vibration absorption bands of $\mathrm{C}=\mathrm{O}$ and $\mathrm{C}-\mathrm{O}$ were detected at $1740 \mathrm{~cm}^{-1}$ and $1068 \mathrm{~cm}^{-1}$, respectively. In addition, the absorption band of $\mathrm{C}-\mathrm{C}$ bonds was detected at at $826 \mathrm{~cm}^{-1}$, and the stretching vibration absorption bands of Ti-S was detected at $603 \mathrm{~cm}^{-1}$, which confirmed main functional groups of TiS.

2.3. Tribological Tests. Tribological properties of $150 \mathrm{SN}$ oils containing additives were evaluated with four ball tester at a rotating speed of $1450 \mathrm{rpm}$ and room temperature about $20^{\circ} \mathrm{C}$. The balls used in the tests were made of GCr 15 bearing steel (AISI 52100) at a diameter of $12.7 \mathrm{~mm}$ with HRC of 59 to 61 . All balls were ultrasonically rinsed with petroleum ether for $10 \mathrm{~min}$ before the experiment.

The antiwear properties of oils were evaluated under loads of 392,490 , and $588 \mathrm{~N}$, respectively, for $60 \mathrm{~min}$ according to ASTM D4172-82, and they were characterized by average wear scar diameters (WSD). An optical microscope was used to determine the wear scar diameters of the three lower balls with an accurate reading to $0.01 \mathrm{~mm}$. Then, the average of the three wear scar diameters was calculated and cited as the wear scar diameter reported in this paper.

The load-carrying capacities of oils were characterized as maximum nonseizure load $\left(P_{\mathrm{B}}\right.$ value $)$ and weld load $\left(P_{\mathrm{D}}\right.$ value), which was evaluated by a short extreme pressure test (10 s) according to ASTM D2783-88.

2.4. Surface Analysis. The chemical states of rubbing surface on the worn scar were investigated using an X-ray photoelectron spectrometer (XPS), which was conducted using a PHI-6100 electrometer. The radiation source was $\mathrm{Mg} \mathrm{Ka}$ line with pass energy of $29.35 \mathrm{eV}$. All binding energies were compared with a reference standard of $284.6 \mathrm{eV}$ for carbon. Profiles and elemental distributions of the worn scar were obtained using the CSM-950 scanning electron microscopy
(SEM) with energy dispersive X-ray (EDX) analysis. Particular attention was paid to the atomic concentration of elements on the worn scars of the steel balls. Before XPS and SEM analysis, all samples were ultrasonically rinsed with hexane and petroleum ether for $10 \mathrm{~min}$.

\section{Results and Discussion}

3.1. Antiwear and Load-Carrying Properties of BNO with TiDDC in Mineral Oil. In order to limit phosphorous content in engine oils, the authors select titanium dibutyldithiocarbamates (TiDDC) to replace zinc dialkyldithiophosphate (ZDDP). TiDDC and organic borate ester (BNO) were added to $150 \mathrm{SN}$ base oil in different proportions; the wear scar diameters (WSD) of balls lubricated by different oil formulations under different loads are reported in Table 1 . It shows that the TiDDC and BNO additives all exhibit better antiwear properties than base oil at each experimental load, and the antiwear properties of TiDDC are better than ZDDP under the same condition. When TiDDC was combined with BNO, at constant total concentration of the package, they possess good antiwear properties in oils. Especially, at the concentration of BNO lower than or equal to TiDDC in base oils, they exhibit good antiwear synergism. For instance, the mixtures of $0.25 \%$ BNO with $0.75 \%$ TiDDC exhibit the best antiwear synergism, and the mixtures $0.5 \% \mathrm{BNO}$ with $1.0 \%$ are better.

The $P_{\mathrm{B}}$ and $P_{\mathrm{D}}$ values of oils containing different additives are summarized in Table 2; the results show that TiDDC and BNO could improve the load-carrying properties (enhance $P_{\mathrm{B}}$ and $P_{\mathrm{D}}$ values) of $150 \mathrm{SN}$ base oils, respectively, and extreme pressure properties of TiDDC is better than BNO. At constant total concentration of the additives, the combination of BNO with TiDDC also could improve $P_{\mathrm{B}}$ and $P_{\mathrm{D}}$ values of base oils comparing with the same dosage of TiDDC.

In order to investigate antiwear synergism between TiDDC and BNO, the worn surface of the ball lubricated by $150 \mathrm{SN}$ oils containing $1.0 \%$ TiDDC and $0.5 \%$ BNO was analyzed by XPS, SEM, and EDX. The binding energy of $\mathrm{B}_{1 \mathrm{~s}}$, $\mathrm{N}_{1 \mathrm{~s}}, \mathrm{O}_{1 \mathrm{~s}}, \mathrm{Fe}_{2 \mathrm{p}}, \mathrm{S}_{2 \mathrm{p}}$, and $\mathrm{Ti}_{2 \mathrm{p}}$ XPS spectra on the worn surface under $490 \mathrm{~N}$ and the main compounds is summarized in Table 3, from which we can conclude that titanium oxides, sulfide, N-containing compound, and iron oxides were formed on the worn surfaces under the tribostressed process.

The profiles and elemental distribution on the wear scars at $392 \mathrm{~N}, 490$, and $588 \mathrm{~N}$ are shown in Figures 1(a)-1(e) and Figures 2(a)-2(c), and the atomic concentration of the elements on the wear scars is listed in Table 4. As displayed in Figure 1, the worn surface of the balls lubricated by $150 \mathrm{SN}$ oil containing $1.0 \%$ TiDDC and $0.5 \% \mathrm{BNO}$ is smoother than the worn surface of oils containing only $2.0 \%$ TiDDC or $2.0 \%$ BNO under the load of $588 \mathrm{~N}$, and the area of worn scar at each load is smaller than TiDDC or BNO. Moreover, the enlarged micrographs $(\times 1500)$ confirm the scratched surface of wear scar lubricated by specific oils. Especially, the rubbing surfaces of wear scar lubricated by BNO or TiDDC only had already been broken to different degrees at the same load. However, the rubbing surfaces of wear scar lubricated 
TABle 1: Antiwear properties of TiDDC and BNO.

\begin{tabular}{lccc}
\hline Samples & & Wear scar diameter, mm & \\
& $392 \mathrm{~N}$ & $490 \mathrm{~N}$ & 1.12 \\
\hline $150 \mathrm{SN}$ & 0.63 & 0.69 & Failure \\
$+1.0 \%$ BNO & 0.49 & 0.72 & Failure \\
$+2.0 \%$ BNO & 0.47 & 0.62 & 1.18 \\
$+1.0 \%$ TiDDC & 0.52 & 0.64 & 1.09 \\
$+2.0 \%$ TiDDC & 0.51 & 0.71 & 1.04 \\
$+1.0 \%$ ZDDP & 0.51 & 0.46 & 1.21 \\
$+1.0 \%$ TiDDC $+1.0 \%$ BNO & 0.39 & 0.52 & 0.97 \\
$+0.25 \%$ TiDDC $+0.75 \%$ BNO & 0.42 & 0.49 & 0.78 \\
$+0.5 \%$ TiDDC $+0.5 \%$ BNO & 0.40 & 0.44 & 0.75 \\
$+0.75 \%$ TiDDC $+0.25 \%$ BNO & 0.39 & 0.46 & 0.51 \\
$+1.0 \%$ TiDDC $+0.5 \%$ BNO & 0.38 & & 0.50 \\
\hline
\end{tabular}

TABLE 2: Load-carrying properties of TiDDC and BNO.

\begin{tabular}{lcc}
\hline Samples & Maximum nonseizure load $P_{\mathrm{B}}, \mathrm{N}$ & Weld load $P_{\mathrm{D}}, \mathrm{N}$ \\
\hline $150 \mathrm{SN}$ & 392 & 1236 \\
$+1.0 \%$ BNO & 647 & 1569 \\
$+1.0 \%$ TiDDC & 745 & 1961 \\
$+1.0 \%$ TiDDC $+1.0 \%$ BNO & 862 & 1961 \\
$+0.25 \%$ TiDDC $+0.75 \%$ BNO & 696 & 1569 \\
$+0.5 \%$ TiDDC $+0.5 \%$ BNO & 745 & 1569 \\
$+0.75 \%$ TiDDC $+0.25 \%$ BNO & 745 & 1569 \\
$+1.0 \%$ TiDDC $+0.5 \%$ BNO & 804 & 1961 \\
\hline
\end{tabular}

TABLE 3: Binding energy of elements on the worn surface and the main compounds.

\begin{tabular}{|c|c|c|c|c|c|c|}
\hline \multirow{2}{*}{ Compounds } & \multicolumn{6}{|c|}{ Binding energy, $\mathrm{eV}$} \\
\hline & $\mathrm{B}_{1 \mathrm{~s}}$ & $\mathrm{~N}_{1 \mathrm{~s}}$ & $\mathrm{O}_{1 \mathrm{~s}}$ & $\mathrm{Fe}_{2 p}$ & $S_{2 p}$ & $\mathrm{Ti}_{2 p}$ \\
\hline & \multicolumn{6}{|c|}{ Tribostressed sample } \\
\hline \multirow[t]{2}{*}{$+0.5 \% \mathrm{BNO}+1.0 \% \mathrm{TiDDC}$} & 190.3 & 400.1 & 529.9 & 710.8 & 160.7 & 458.5 \\
\hline & \multicolumn{6}{|c|}{ Reference compounds } \\
\hline N-containing compounds & & 399.8 & & & & \\
\hline $\mathrm{FeS}$ & & & & 710.8 & 161.6 & \\
\hline $\mathrm{Fe}_{2} \mathrm{O}_{3}$ & & & 529.6 & 710.9 & & \\
\hline $\mathrm{TiO}_{2}$ & & & 529.7 & & & 458.3 \\
\hline
\end{tabular}

by oil containing BNO with TiDDC are uniform and smooth at each load, which contributed to the development of thick lubricating films caused by faster deposition rate than the wear rate of films. While for the individual components, the wear rate is faster than the deposition rate, so as the lubricating films are thinner. Therefore, the SEM analysis of the worn surfaces also confirms the synergistic effects of TiDDC with BNO additives on the antiwear properties.

The data in Table 4 were obtained from Figures 2(a)-2(c) using a computer program and normalized to 100 for all given compositions. It was discovered that the contents of $\mathrm{Ti}$ and $\mathrm{S}$ atoms on the worn surface were decreased with the increase of the loads. These changes suggest that the increase of loads would result in greater wear rate than the forming rate of the lubricating film, thus leading to the decrease of $S$ and $\mathrm{Ti}$ contents, which is consistent with the increase of WSD. Though TiDDC additive contains higher contents of $S$ and $\mathrm{Ti}$ than the complex of TiDDC and BNO additive, the contents of $\mathrm{Ti}$ on the wear scars from oils containing $1.0 \%$ TiDDC under $490 \mathrm{~N}$ are less than that of the complex; the atomic concentration of $\mathrm{Ti}$ is 0.756 in Figure 3. These observations indicate that the titanium oxides formed on the worn surface play an important role in improving antiwear properties of lubricants.

3.2. Antiwear and Load-Carrying Properties of TiS with BNO in Mineral Oil. Sulfurized titanate (TiS) and organic borate ester (BNO) were added to $150 \mathrm{SN}$ base oil, and the wear scar diameters (WSD) of tested balls are listed in Table 5. We can see clearly that TiS or BNO additives possess better antiwear properties than base oils at each experimental load, and the antiwear properties of BNO is better than TiS at the same condition. Moreover, there are no obvious changes that occurred with the increase of additive concentration. When TiS is combined with $\mathrm{BNO}$, the antiwear properties of 


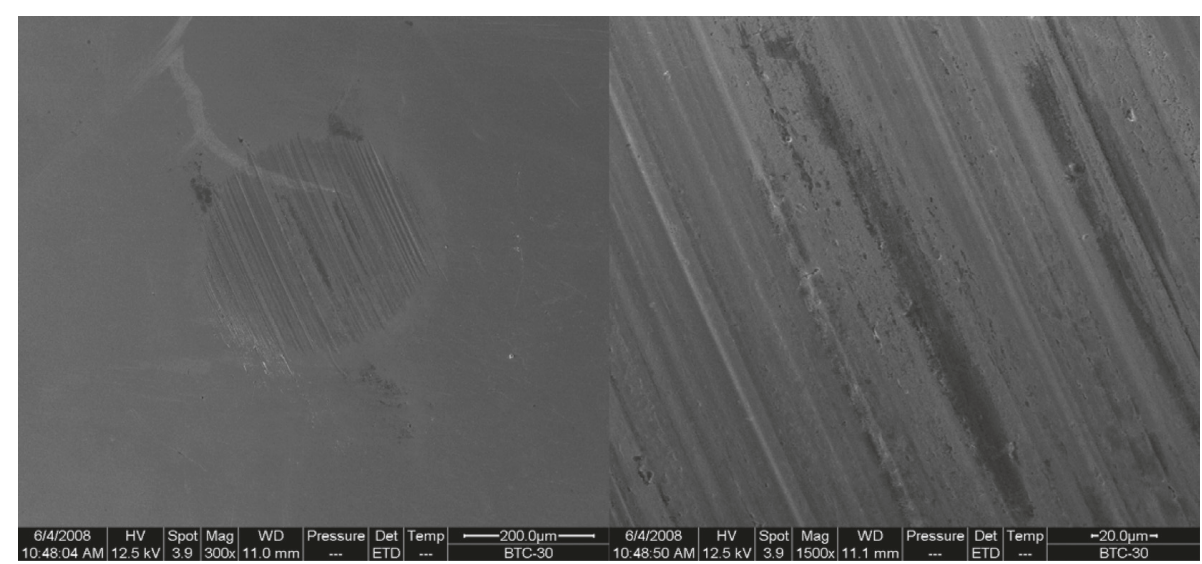

(a)

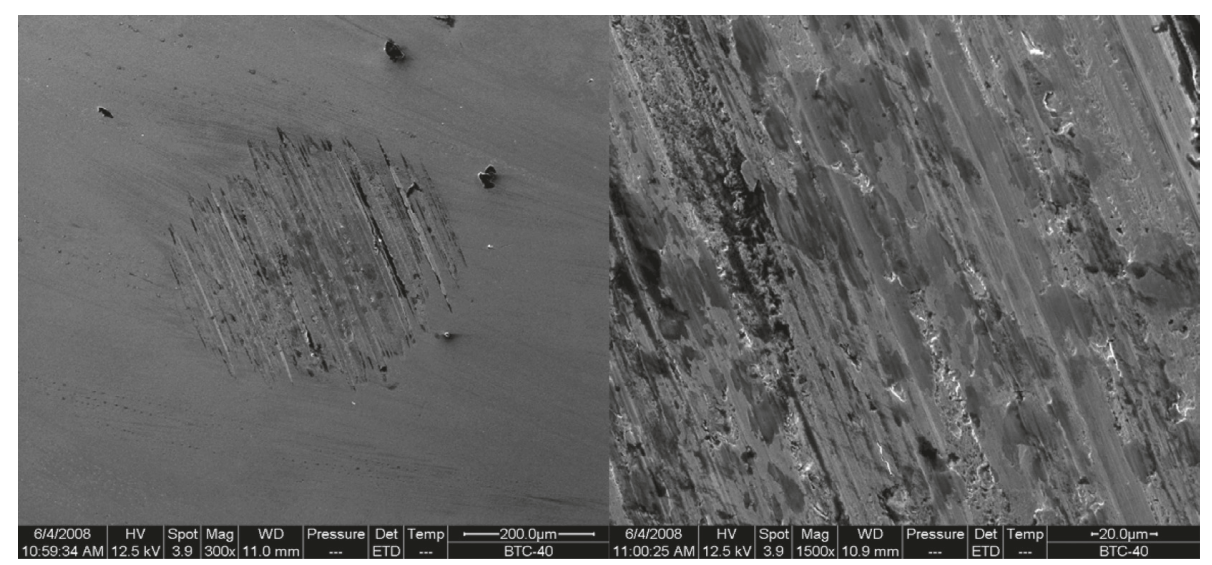

(b)

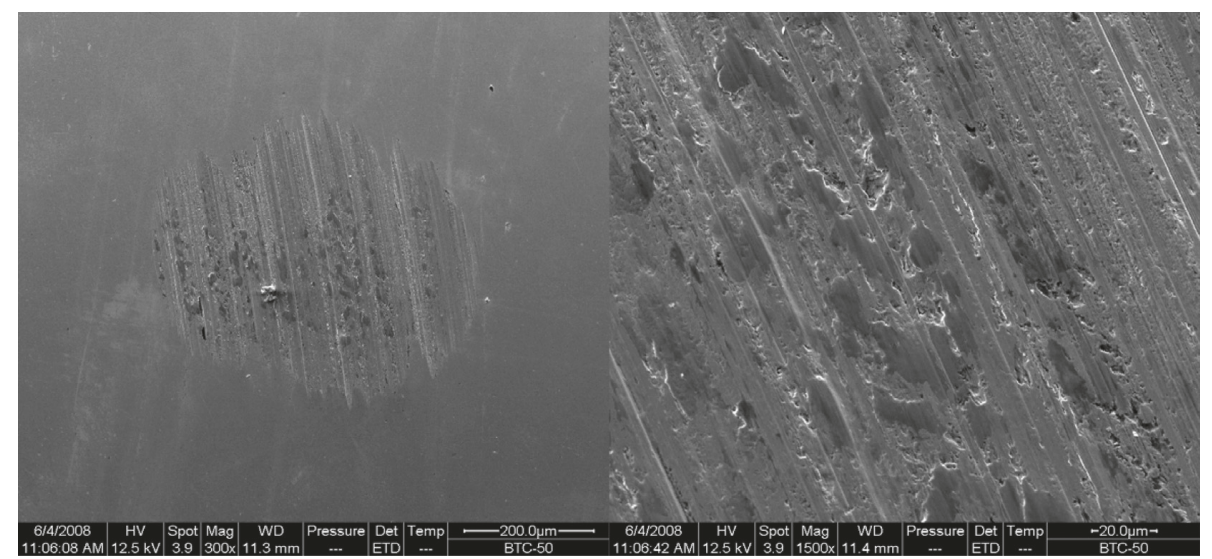

(c)

FIgUre 1: Continued. 


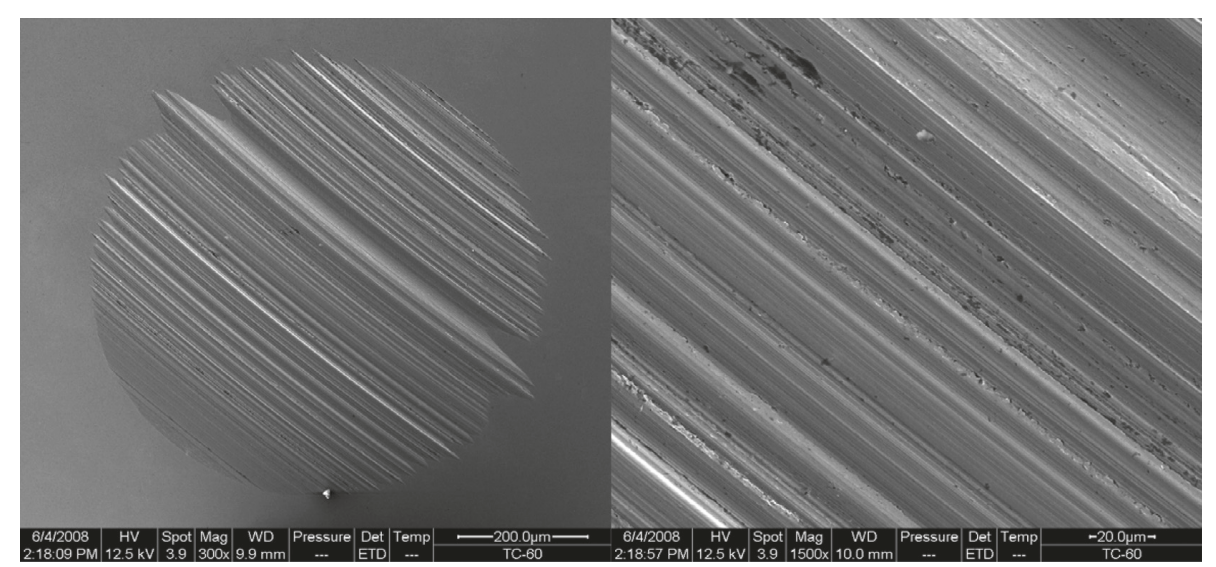

(d)

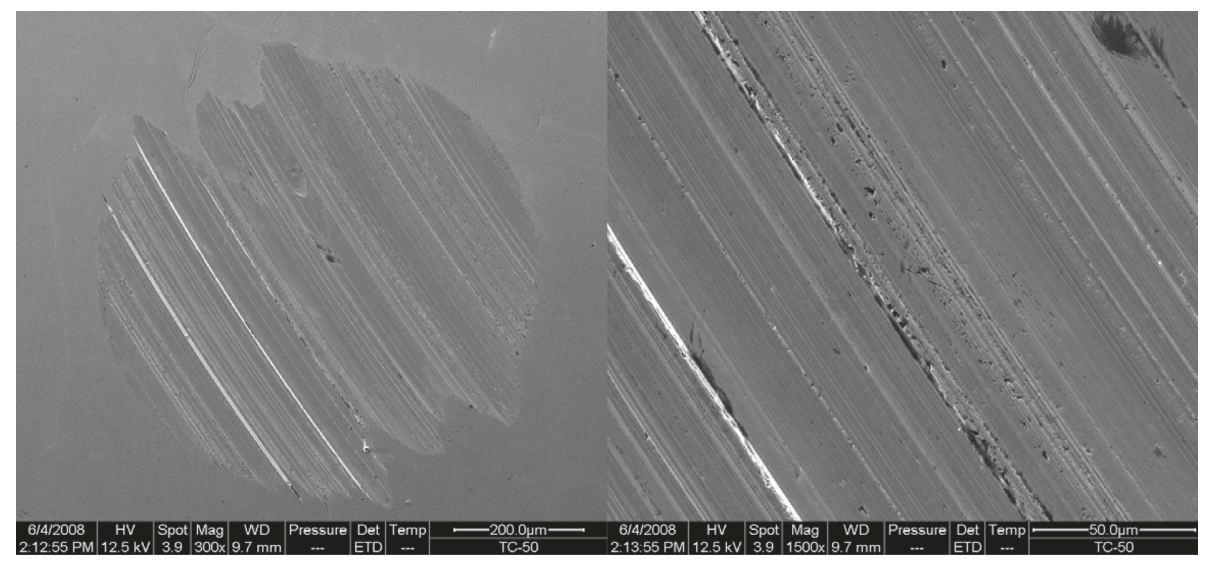

(e)

FIGURE 1: SEM photographs of worn scar lubricated by different oils under different loads: (a) oil containing TiDDC and BNO at 392 N; (b) oil containing TiDDC and BNO at $490 \mathrm{~N}$; (c) oil containing TiDDC and BNO at $588 \mathrm{~N}$; (d) oil containing TiDDC at $588 \mathrm{~N}$; (e) oil containing $\mathrm{BNO}$ at $588 \mathrm{~N}$.

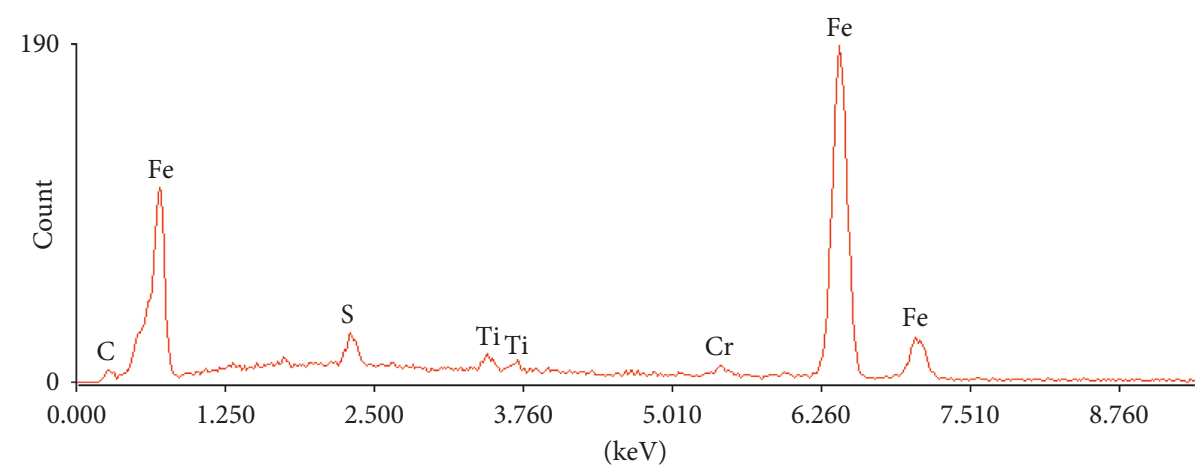

(a)

FIGURE 2: Continued. 


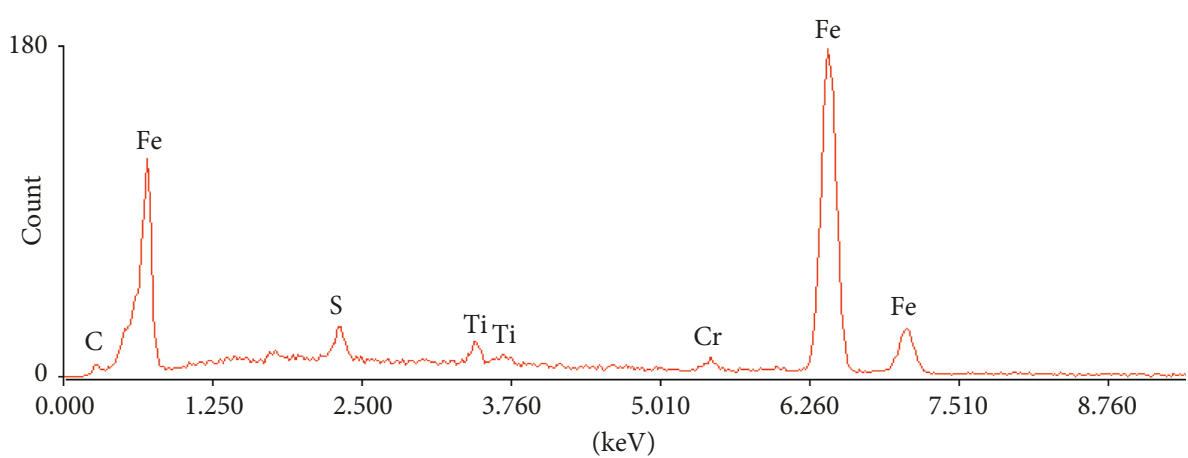

(b)

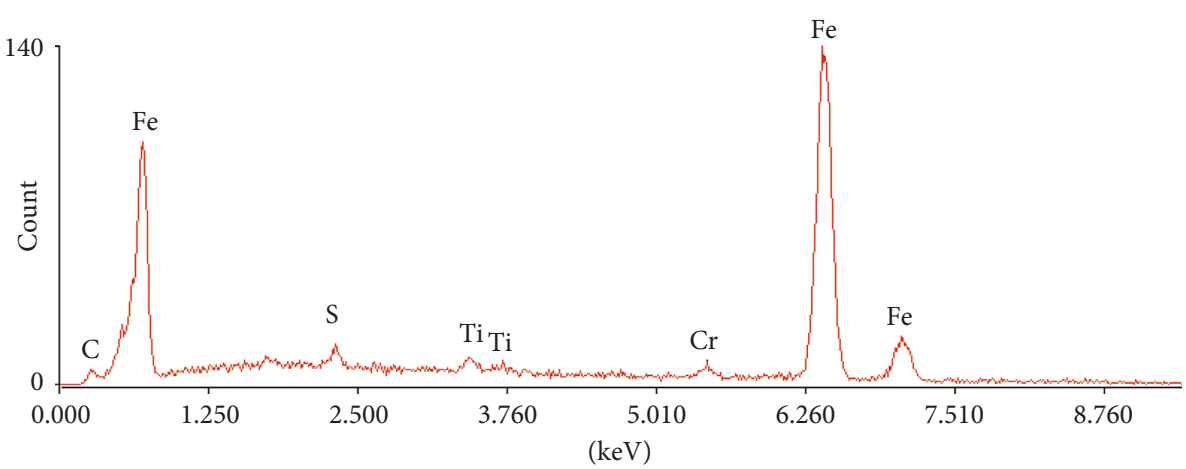

(c)

FIGURE 2: EDX spectra of wear scars under different loads: (a) $392 \mathrm{~N}$; (b) $490 \mathrm{~N}$; (c) $588 \mathrm{~N}$.

TAble 4: Atomic concentration (\%) of elements on the wear scar by EDX.

\begin{tabular}{lcccrr}
\hline Analytic area & C & S & Cr & Fe & Ti \\
\hline Wear scar at 392 N & 2.624 & 4.342 & 1.321 & 90.078 & 1.635 \\
Wear scar at 490 N & 0.558 & 2.590 & 1.740 & 93.150 & 1.418 \\
Wear scar at 588 N & 0.793 & 1.521 & 1.420 & 95.289 & 0.977 \\
\hline
\end{tabular}

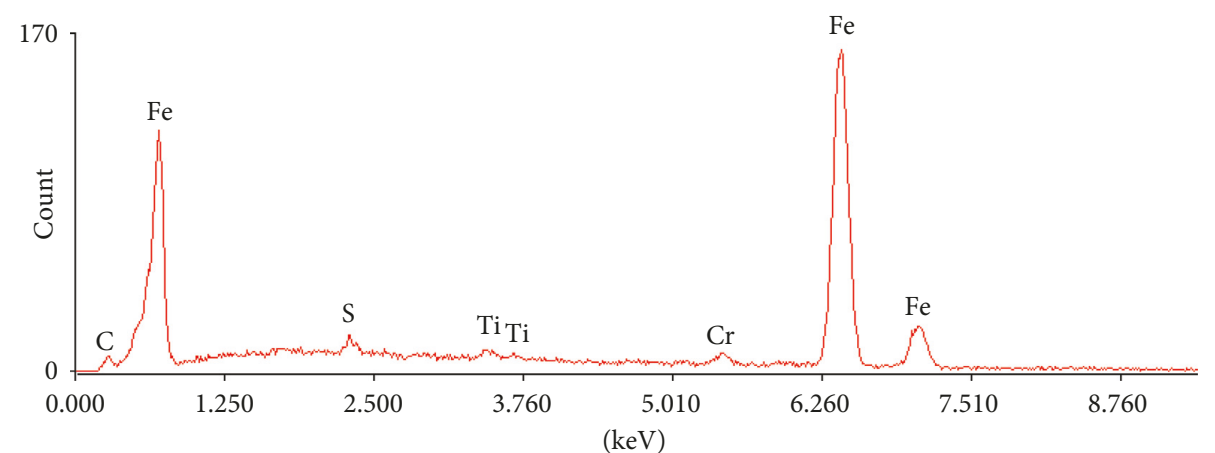

FIgure 3: EDX spectra of wear scars with 1.0\% TiDDC under $490 \mathrm{~N}$.

lubricants are enhanced at different degrees compared with each alone. For instance, at constant total concentration of additive package, the WSD of the oils containing $0.75 \%$ TiS and $0.25 \% \mathrm{BNO}$ are lower than that of oils containing $1.0 \%$ TiS or $1.0 \%$ BNO alone. The WSD of oils containing $1.0 \%$ BNO with $1.0 \%$ TiS are lower than that of oils containing
$2.0 \%$ BNO or $2.0 \%$ TiS alone, which are confirmed by SEM photographs of worn scar displayed in Figures 4(a)-4(d).

The $P_{\mathrm{B}}$ and $P_{\mathrm{D}}$ values of oil containing different additives are listed in Table 6; the results shows that the addition of TiS and $\mathrm{BNO}$ to base oils could all improve the load-carrying properties ( $P_{\mathrm{B}}$ and $P_{\mathrm{D}}$ values), and TiS is better than BNO. 
TABle 5: Antiwear properties of TiS and BNO.

\begin{tabular}{lccc}
\hline Samples & & WSD, mm & $588 \mathrm{~N}$ \\
\hline $150 \mathrm{SN}$ & $392 \mathrm{~N}$ & $490 \mathrm{~N}$ & Failure \\
$+1.0 \%$ BNO & 0.63 & 1.12 & Failure \\
$+2.0 \%$ BNO & 0.49 & 0.69 & 1.18 \\
$+1.0 \%$ TiS & 0.47 & 0.72 & 1.06 \\
$+2.0 \%$ TiS & 0.62 & 0.85 & 0.98 \\
$+1.0 \%$ TiS + $1.0 \%$ BNO & 0.61 & 0.86 & 0.92 \\
$+0.25 \%$ TiS $+0.75 \%$ BNO & 0.33 & 0.71 & 1.56 \\
$+0.5 \%$ TiS $+0.5 \%$ BNO & 0.44 & 0.94 & 1.67 \\
$+0.75 \%$ TiS $+0.25 \%$ BNO & 0.47 & 0.68 & 0.83 \\
$+0.5 \%$ TiS $+1.0 \%$ BNO & 0.43 & 0.51 & 1.12 \\
\hline
\end{tabular}

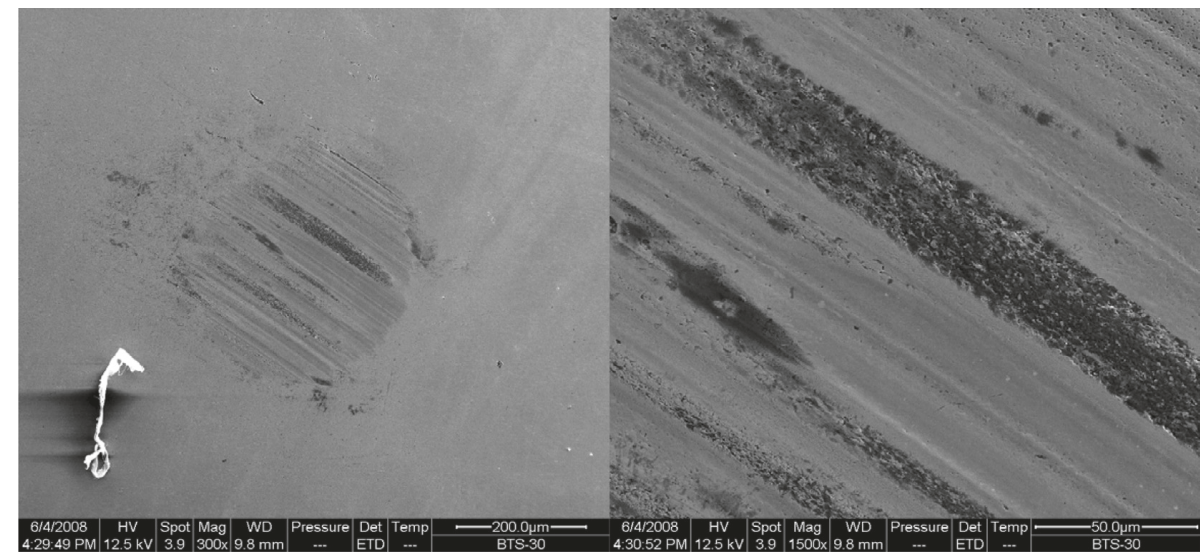

(a)

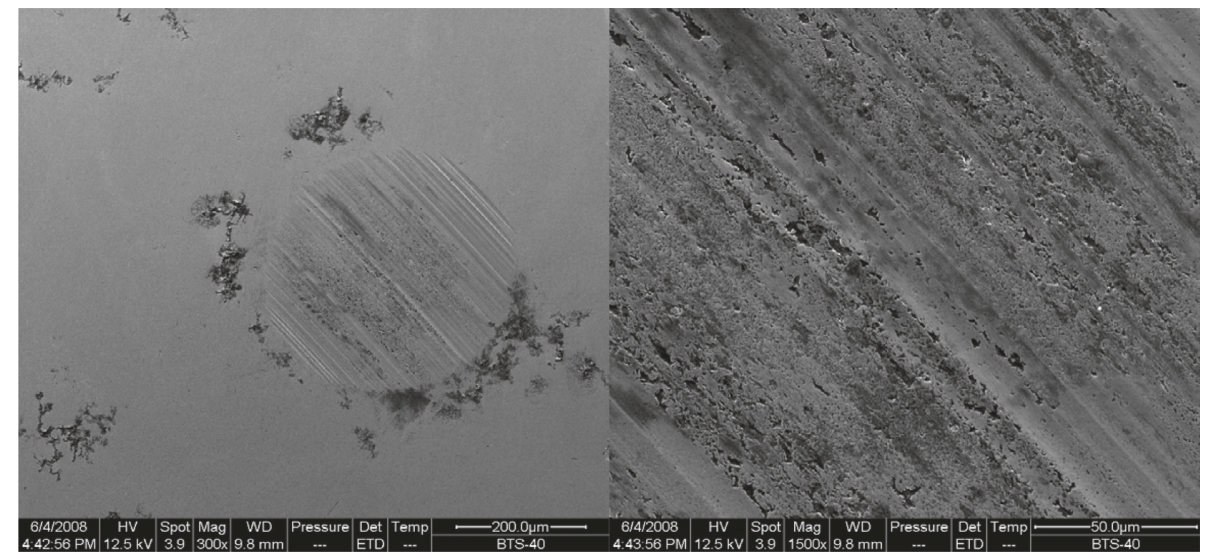

(b)

Figure 4: Continued. 


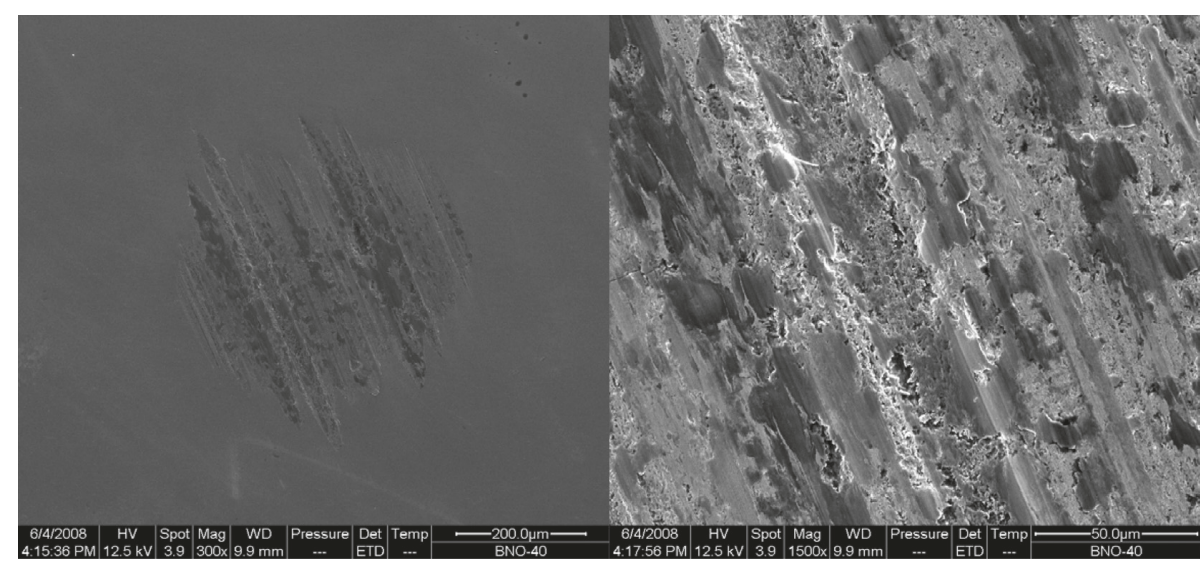

(c)

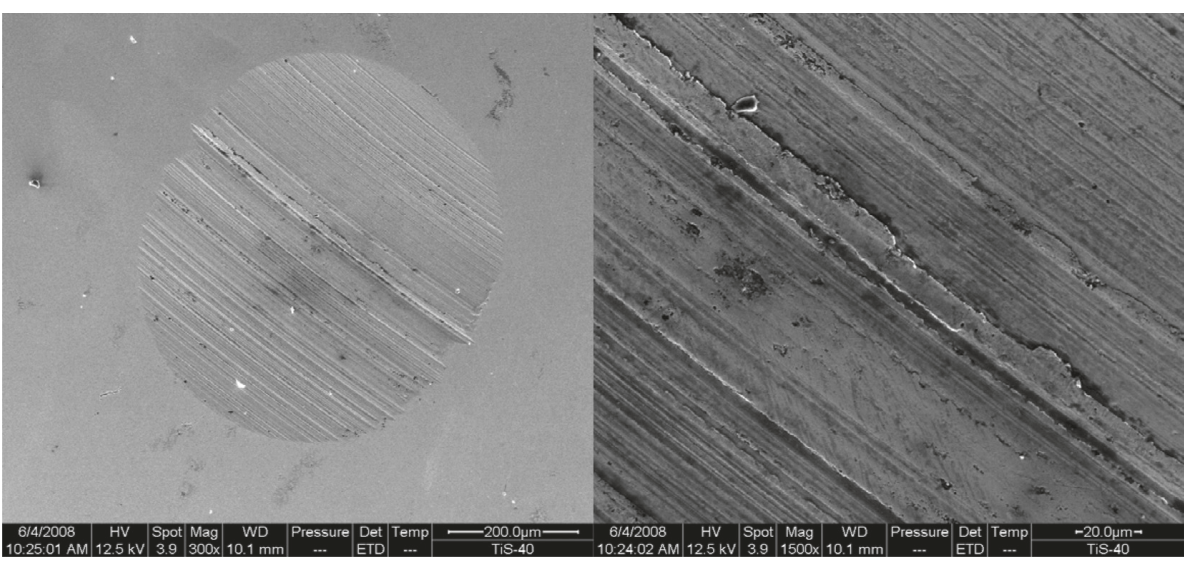

(d)

FIGURE 4: SEM photographs of worn scar lubricated with additive containing oil under different loads: (a) BNO with TiS at 392 N; (b) BNO with TiS at $490 \mathrm{~N}$; (c) BNO at $490 \mathrm{~N}$; (d) TiS at $490 \mathrm{~N}$.

TABLE 6: Load-carrying capacities of BNO mixed with TiS.

\begin{tabular}{lcc}
\hline Samples & $\begin{array}{c}\text { Maximum nonseizure load } \\
P_{\mathrm{B}}, \mathrm{N}\end{array}$ & $\begin{array}{c}\text { Weld load } \\
P_{\mathrm{D}}, \mathrm{N}\end{array}$ \\
\hline $150 \mathrm{SN}$ & 392 & 1236 \\
$+1.0 \% \mathrm{BNO}$ & 647 & 1569 \\
$+1.0 \% \mathrm{TiS}$ & 745 & 1569 \\
$+1.0 \% \mathrm{TiS}+1.0 \%$ & 921 & 1961 \\
$\mathrm{BNO}$ & & \\
$+0.25 \% \mathrm{TiS}+0.75 \%$ & 647 & 1569 \\
BNO & & \\
$+0.5 \% \mathrm{TiS}+0.5 \%$ & 647 & 1569 \\
BNO & & \\
$+0.75 \% \mathrm{TiS}+0.25 \%$ & 745 & 1961 \\
BNO & & \\
$+0.5 \% \mathrm{TiS}+1.0 \%$ & 862 & \\
BNO & & \\
\hline
\end{tabular}

When BNO is combined with TiS, at constant total concentration of the additive packages, the $P_{\mathrm{B}}$ and $P_{\mathrm{D}}$ values of the base oils containing TiS and BNO were enhanced at different degrees and similar to the same dosage of TiS. For instance, the mixtures of oil containing $0.75 \%$ TiS and $0.25 \%$ $\mathrm{BNO}$ are almost equal to $1.0 \%$ TiS alone, so does the oil containing $1.0 \% \mathrm{TiS}$ and $1.0 \%$ BNO.

\section{Conclusion}

(1) Titanium dibutyldithiocarbamates (TiDDC) as lubricant additive possess better antiwear properties than ZDDP. Though the combination of TiDDC with BNO might influence their performance negatively, the concentration of $\mathrm{BNO}$ is lower than TiDDC under the constant sum of dosage, and the good antiwear synergism was obtained.

(2) Sulfurized titanate (TiS) as lubricant additive also possesses better antiwear properties than ZDDP; when TiS was combined with BNO in base oils, they exhibit good synergistic antiwear properties.

(3) Even with the small additions of described above, nearly half of the phosphorus from ZDDP can be beneficially replaced by smaller amounts of boron in the lubricating oils, and the phosphorus in the lubricants may be removed with addition of TiDDC with BNO. These open up an opportunity for the formulation of friendly additive packages, which deserves to be the object of more detailed studies related to particular lubricant specifications. 


\section{Data Availability}

The data used to support the findings of this study are included within the article.

\section{Conflicts of Interest}

The authors declare that they have no conflicts of interest.

\section{Acknowledgments}

This work was subsidized by funds from the National Natural Science Foundation of China (Grant 51575525) and the Natural Science Foundation of Jiangsu Province (Grant BK20151137, BK20161188). The project was also supported by the Tribology Science Fund of the State Key Laboratory of Tribology (Grant SKLTKF17B11).

\section{References}

[1] G. Liskiewicz, P. Kula, A. Neville, R. Pietrasik, A. Morina, and T. Liskiewicz, "Hydrogen influence on material interaction with ZDDP and MoDTC lubricant additives," Wear, vol. 297, no. 1-2, pp. 966-971, 2013.

[2] Z. Jie and H. Spikes, "On the mechanism of ZDDP antiwear film formation," Tribology Letters, vol. 63, no. 2, pp. 1-15, 2016.

[3] Y. Matsui, S. Aoki, Q. Kurosawa, and M. Masuko, "Concert and blocking effects of polar compounds on the friction reduction and tribofilm formation of zinc dialkyldithiophosphate," Tribology Online, vol. 11, no. 2, pp. 417-425, 2016.

[4] S. Bec, A. Tonck, J. M. Georges, and G. W. Roper, "Synergistic effects of MoDTC and ZDTP on frictional behaviour of tribofilms at the nanometer scale," Tribology Letters, vol. 17, no. 4, pp. 797-809, 2004.

[5] E. S. Yamaguchi, A. Onopchenko, M. M. Franciso, and C. Y. Chan, "The relative oxidation inhibition performance of some neutral and basic zinc dithiophosphate salts," Tribology Transaction, vol. 42, no. 4, pp. 895-901, 1999.

[6] H. Gao, J. S. McQueen, E. D. Black, A. K. Gangopadhyay, and R. K. Jensen, "Reduced phosphorus concentration effects on tribological performance of passenger car engine oils," Tribology Transaction, vol. 47, no. 2, pp. 200-207, 2004.

[7] K. Hakan, "The impact of crankcase oil containing phosphorus on catalytic converters and engine exhaust emission," Industrial Lubrication and Tribology, vol. 53, no. 6, pp. 237255, 2001.

[8] A. M. Barnes, K. D. Bartle, and V. R. A. Thibon, "A review of zinc dialkyldithiophosphates (ZDDPS): characterization of and role in lubricating oil," Triboloy International, vol. 34, no. 6, pp. 389-395, 2001.

[9] H. A. Spikes, "The history and mechanisms of ZDDP," Tribology Letters, vol. 17, no. 3, pp. 469-489, 2004.

[10] H. A. Spikes, "Low-and zero-sulphated ash, phosphorus and sulphur anti-wear additives for engine oils," Lubrication Science, vol. 20, no. 2, pp. 103-136, 2008.

[11] J. Styer and G. Guinther, "Fuel economy beyond ILSAC GF-5: correlation of modern engine oil tests to real world performance," SAE International Journal of Fuels and Lubricants, vol. 5, no. 3, pp. 1025-1033, 2012.
[12] A. K. Gangopadhyay, R. K. Jensen, R. O. Carter et al., "Development of zero-phosphorus engine oils," Lubrication Science, vol. 20, no. 2, pp. 163-180, 2008.

[13] H. Liu, J. J. Jin, H. Y. Li et al., "0W-16 fuel economy gasoline engine oil compatible with low speed pre-ignition performance," SAE International Journal of Fuels and Lubricants, vol. 10, no. 3, pp. 842-847, 2017.

[14] W. Y. Lam, J. T. Loper, C. K. Esche et al., "Titaniumcontaining lubricating oil composition," U.S. Patent 7879774, 2011.

[15] N. C. Mathurr and J. M. Guevremont, "Method for making a titanium-containing lubricant additive," U.S. Patent 8008237, 2011.

[16] T. A. Zaimovskaya, E. Y. Oganesova, G. N. Kuzmina, A. A. Ezhov, V. K. Ivanov, and O. P. Parenago, "Titaniumcontaining compounds as efficient triboadditives to oils," Journal of Friction and Wear, vol. 34, no. 6, pp. 487-493, 2013.

[17] E. Y. Oganesova, G. N. Kuz’Min, E. G. Bordubanova et al., "Comparison of antiwear properties of titanium-containing compounds," Petroleum Chemistry, vol. 52, no. 3, pp. 204207, 2012

[18] R. Zahid, M. B. H. Hassan, M. Varman et al., "A review on effects of lubricant formulations on tribological performance and boundary lubrication mechanisms of non-doped DLC/ DLC contacts," Critical Reviews in Solid State and Materials Sciences, vol. 42, no. 4, pp. 267-294, 2017.

[19] J. Qu, W. C. Barnhill, H. M. Luo et al., "Synergistic effects between phosphonium-alkylphosphate ionic liquids and zinc dialkyldithiophosphate (ZDDP) as lubricant additives," $\mathrm{Ad}$ vanced Materials, vol. 27, no. 32, pp. 4767-4774, 2015.

[20] Y. Li, S. W. Zhang, Q. Ding, H. Li, B. F. Qin, and L. T. Hu, "Understanding the synergistic lubrication effect of 2-mercaptobenzothiazolate based ionic liquids and Mo nanoparticles as hybrid additives," Triboloy International, vol. 125, no. 1, pp. 39-45, 2018.

[21] X. S. Fu, J. C. Li, L. G. Sun, X. G. Zhou, B. J. Fan, and T. H. Ren, "Synergistic effect between organic borate esters and phosphorus-based additives on tribological performances as lubricant additives in mineral oil," Proceedings of the Institution of Mechanical Engineers Part J-Journal of Engineering Tribology, vol. 231, no. 8, pp. 1030-1040, 2017. 

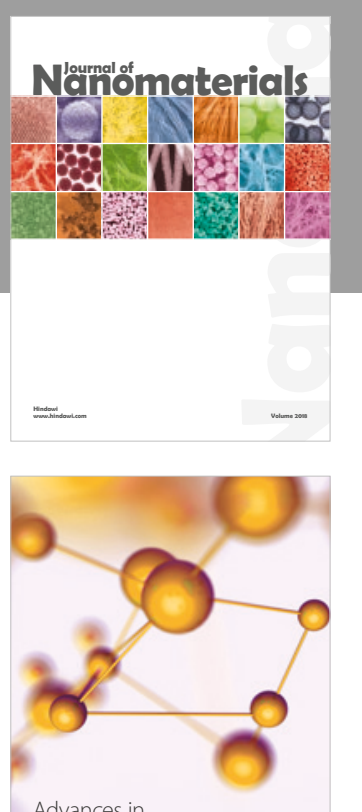

Physical Chemistry
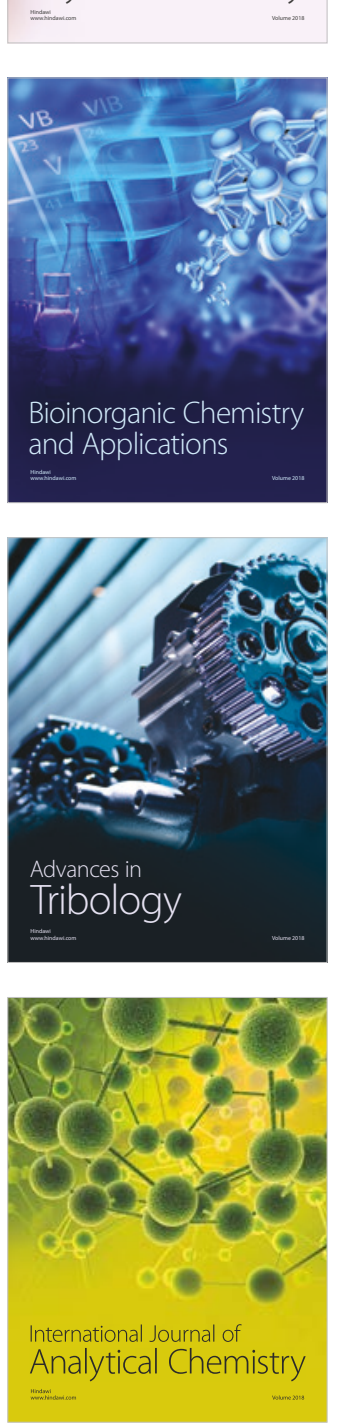

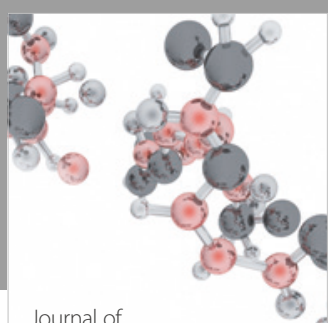

Analytical Methods

in Chemistry

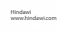

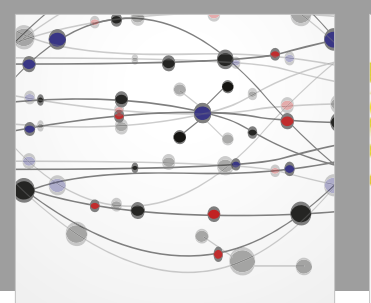

The Scientific World Journal

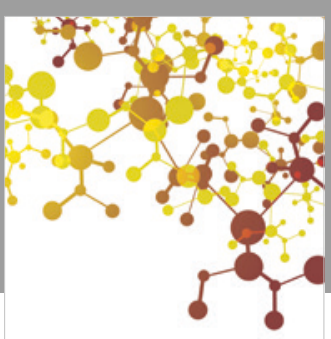

Journal of

Applied Chemistry
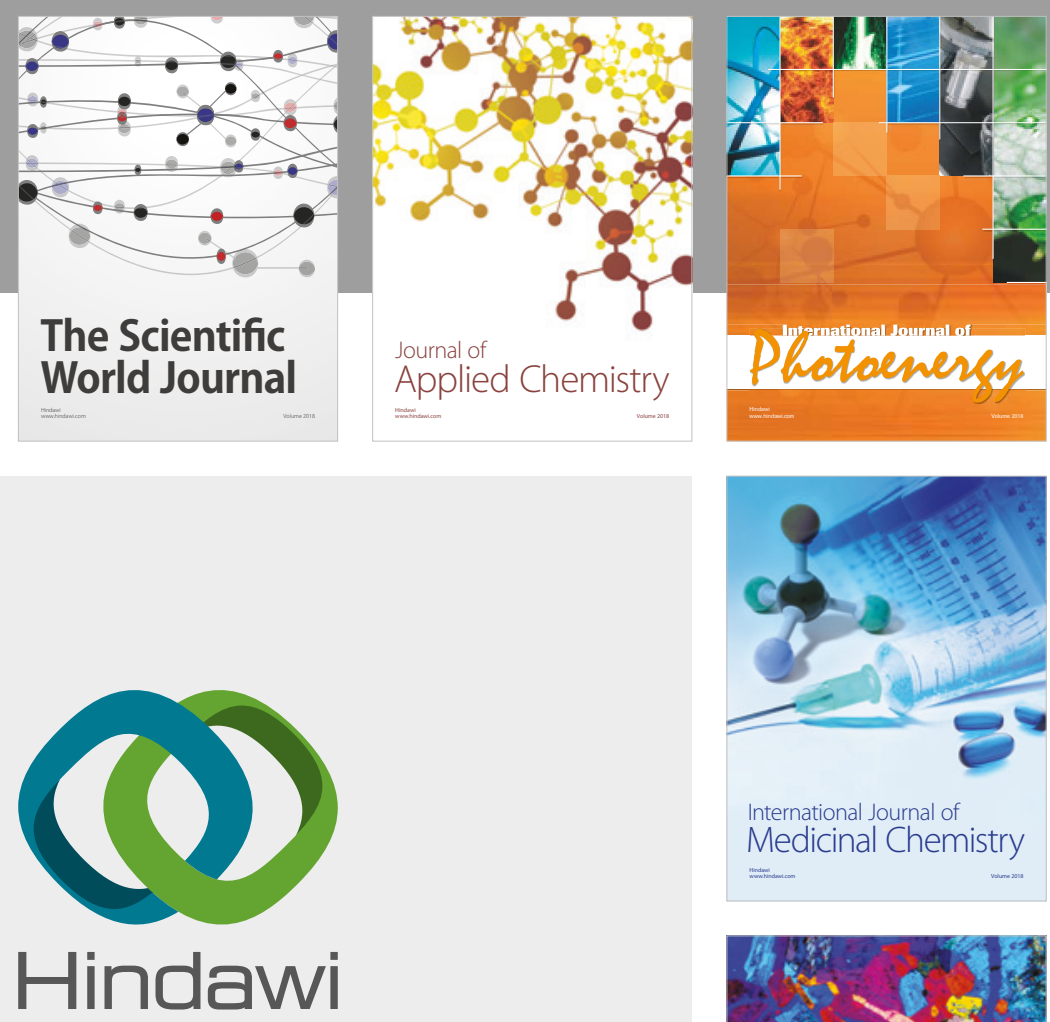

Submit your manuscripts at

www.hindawi.com
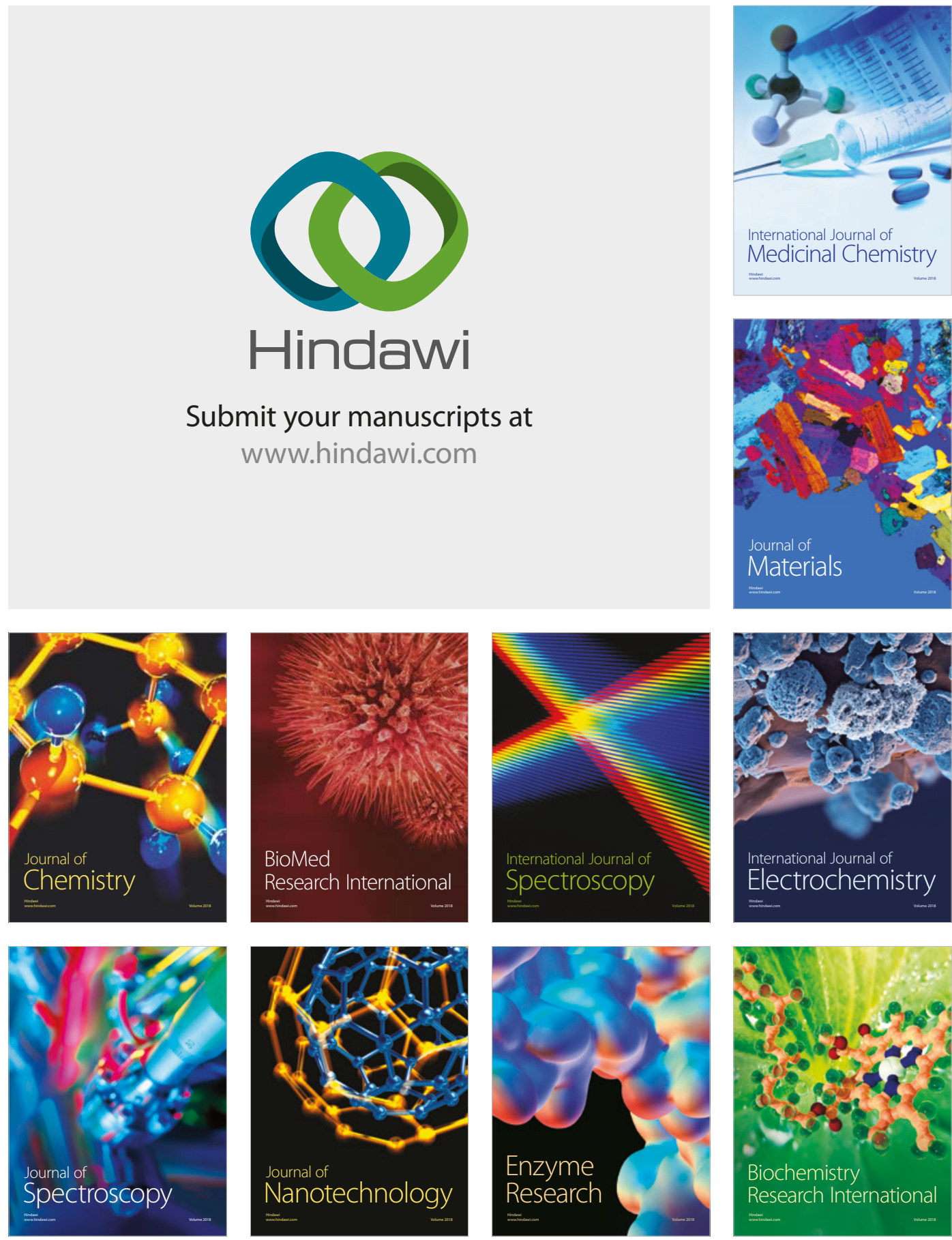
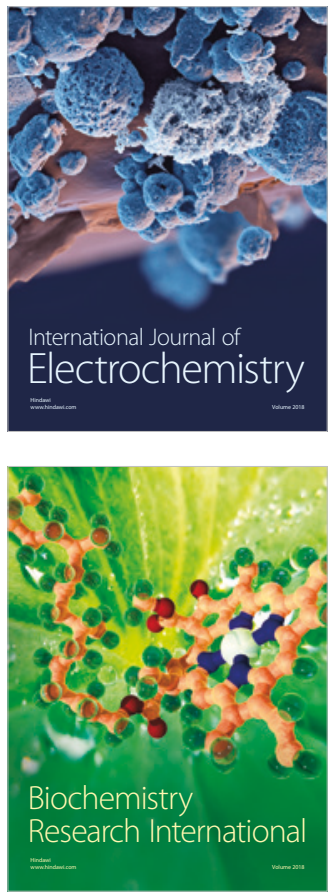